\title{
1. PRIDE \\ Silenced pride in scarce consumption
}

\section{Hanna Leipämaa-Leskinen, Henna Syrjälä and Pirjo Laaksonen}

\section{INTRODUCTION}

In the sixth century $\mathrm{AD}$, Gregory the Great described pride as the root of all seven deadly sins (Timpe and Boyd 2014). Since that time multiple definitions of pride have been offered by the ancient classical and religious philosophers, and more recently by psychological scholars (Belk 1983). To synthesize prior elaborations, Caywood and Langrehr (1990, p.56) define pride as a sin, as "a high opinion of one's own qualities, achievement or possessions" and connect it with arrogance, self-importance, and egoism. Contrary to the "sinful" viewpoint, psychologist scholars also attach positive facets to pride (Tracy and Robins 2007). Within this tradition, pride is seen as a self-caused emotion that is experienced when favorable results are achieved due to an individual's own actions (Soscia 2007). The individual may then be justly proud of herself, her achievements, or her possessions (Zammuner 1996).

Most of the marketing and consumption scholars have focused on the positive facets of pride (Decrop and Derbaix 2010; Verbeke et al. 2004). In fact, Belk's (1983) conceptual paper is the only exception, addressing the sinful perspective of pride (and other deadly sins) in consumption and connecting it with materialism and conspicuous consumption. In this chapter we revisit pride in consumer research, elaborating it in a context in which pride seems at first glance to be missing: namely, in conditions of scarce consumption. In particular, we analyze manifestations of pride in two divergently scarce conditions by taking the perspectives of nonvoluntary and 
voluntary simplifiers. While nonvoluntary simplifiers are forced to limit their consumption due to financial constraints, voluntary simplifiers reduce their consumption for ideological reasons. In this way, we are able to show that by creating pride in these unorthodox conditions, a new facet of pride appears, because these consumers have to negotiate their lifestyle and consumption in relation to the surrounding, abundant consumer culture. Accordingly, the current chapter contributes to existing understandings of pride by showcasing that pride is not simply a negative or positive conceptualization, but appears more multifariously when understood within the discrete layers of consumer society.

In the current analysis, we give voice to the voluntary and nonvoluntary simplifiers through analysis of the written narratives of their everyday lives which they have produced. Thus, by using narrative methodology, we explore how pride emerges in the Finnish nonvoluntary and voluntary simplifiers' lives. The chapter proceeds by reviewing how prior conceptual and empirical research has discussed pride. After that we describe the narrative materials and methods used in this study. The findings showcase two narrative categories of pride in scarce conditions: "forbidden fruit" and "hidden heroism." These, together, construct the third facet of pride - on the side of both positive and negative - known as "silenced pride." The chapter ends by highlighting the need to also explore nontraditional consumption contexts in order to complete our picture of the emergence and the moral aspects of the seven deadly sins in consumer culture.

\section{CONCEPTUALIZING FACETS OF PRIDE}

In conceptualizing pride as a theoretical construct, prior psychological scholars have separated its positive and negative facets. Negative pride is attributed to oneself ("I am a superior person") (Verbeke et al. 2004). It is precisely this "excessive" pride (also called hubris) that feeds an individual's egoism and arrogance, and that can be connected to the seven deadly sins that originate from ancient Greek and biblical thought (McFerran et al. 2011). Indeed, pride consists of feelings of self-sufficiency and is usually manifested by an arrogant disregard for the worth of others (Belk 1983). Pride is often viewed as the opposite to the virtues of courage, modesty, or humility (Timpe and Boyd 2014), which further highlights self-consciousness, ego 
focus, self-importance, and arrogance as traits connected with pride (Caywood and Langrehr 1990).

Pride is, indeed, often paralleled with vanity (Belk 1983). It is suggested, for instance, that individuals are attracted to fashion because of the desire to gain prestige, which acts then as a signal of pride (ibid.). At the cultural level, the metamorphosis of the seven deadly sins (including pride) into an entitlement to endless fulfillment of personal aspirations creates legitimacy for a consumer society that is without constraint or responsibility (Fullerton and Punj 1998). However, these materialistic values, acting as drivers for new material possessions, are also presented as the primary source for criticism of consumption (cf. Burroughs and Rindfleisch 2002). Scarcity and a nonmaterialistic way of living are presented as desirable virtues; for example, Finnish people have traditionally regarded the Protestant work ethic and modesty as admirable (Heinonen and Autio 2013).

When pride is seen as a positive emotion, however, psychological work states that the individual attributes feelings of pride to his or her own behavior or its outcomes: "I performed well" (Verbeke et al. 2004). This is also called "authentic" pride (Tracy and Robins 2007). For instance, Decrop and Derbaix (2010, p.587) define authentic pride as "a feeling of satisfaction, delight or pleasure in something one has achieved and/or one is able to do, or in the achievements and/ or capabilities of someone is connected with." In this respect, pride is paralleled with "feeling proud of," whether what is felt proud of is an achievement or possession of a valued object (Zammuner 1996), and helps an individual to behave in accordance with her personal values and standards (Antonetti and Maklan 2014).

Further, authentic pride is seen to support social identity processes (Decrop and Derbaix 2010), as pride is not just attached to one's own self-appraisal and social status, but is influenced by the opinions of others. The social processes of pride are also addressed by Jasper (2011, p.289), who regards pride and shame as moral emotions of self-approval and self-disapproval, entailing a feeling of connection or disconnection from those around one. Thus, pride is an emotion that may motivate people to join or separate from social groups. Tracy and Robins (2004) have even demonstrated that pride has a recognizable nonverbal expression, showing that it has evolved to serve a particular communicative function.

Pride has also been explored primarily as a positive emotion in the field of marketing and consumer research. In their seminal work of 
1982, Holbrook and Hirschman grouped pride together with many other emotions - such as love, hate, anxiety, disgust, and sadnesswhile addressing the importance of the experiential aspects of consumption. Since then numerous studies have been conducted to specify the interrelations between certain emotions (including pride) and consumption behaviors (Aaker and Williams 1998; Bagozzi et al. 1998; Richins 1997). In these works, pride is seen primarily as a self-caused emotion, albeit one that responds to others' opinions (Roseman 1991).

Pride is often studied alongside shame or guilt (Antonetti and Maklan 2014; Bagozzi et al. 1999; Jasper 2011), as all of these help individuals to control personal decisions in support of long-term goals (Baumeister 2002). These studies try to find out how to appeal to consumers in a way that makes them proud of themselves, their achievements, and their possessions. In this regard, priderelated appeals have been found to increase charitable volunteering (Boezeman and Ellemers 2007), the effects of cause-related marketing campaigns (Kim and Johnson 2013), sustainable marketing initiatives (Antonetti and Maklan 2014), and healthy consumption (Onwezen et al. 2014). Finally, pride has been explored in the case of brand relationships (Bellezza and Keinan 2014), uniqueness-seeking behaviors (Huang et al. 2014), and luxury consumption (McFerran et al. 2011).

Another emphasis has been on investigating how pride works as a mediator between consumers' attitudes, intentions, and (post)consumption behaviors. Particularly apt examples are the papers by Wilcox et al. (2011), who explored the influence of incidental pride on indulgence behavior, and Louro et al. (2005), who investigated how pride affects consumers' repurchase intentions. In addition, Soscia (2007) analyzed the correlation between consumers' emotional experiences and their postconsumption behaviors, showing that pride occurs when an individual sees herself as being responsible for goal-congruent outcomes. Similarly, salespersons' feelings of pride have been found to increase their motivation and have positively affected their prosocial behaviors (Verbeke et al. 2004), as well as making them more self-assured, more creative, and more altruistic (Bagozzi et al. 1999). Decrop and Derbaix (2010) explored pride in the context of fan subcultures, and how pride is manifested in fans' identity processes. Their work represents an exception among the marketing studies discussing pride because it addresses the effects 
of pride at the level of group and community, going beyond the individual perspective.

We can conclude that pride is conceptualized as either positive, connected with the feeling of satisfaction in one's own proper achievements, or negative, connected with unwarranted egoism and arrogance. As shown above, the previous literature has put a stress on pride from the perspective of affluent consumers, whereas this chapter considers the other angle: if and how those whose consumption is characterized by scarcity talk about pride.

\section{NONVOLUNTARY AND VOLUNTARY SCARCITY}

In this chapter, we regard scarce consumption as an umbrella term for varied theoretical constructs, such as sufficiency, frugal consumption, necessity consumption, and anticonsumption (Gorge et al. 2015; Lee et al. 2009; Leipämaa-Leskinen et al. 2016; Pepper et al. 2009), all of which have been used to refer to limiting consumption amounts. The reasons for scarcity may differ, however, being due to personal wellbeing, connected to attempts at a sustainable lifestyle, or caused by financial reasons or obligations, for example. Nevertheless, scarce consumption always relates to decreasing material and energydemanding consumption (food, energy, clothes, and other consumer goods; transportation, and so on), as well as questioning living choice and consumption norms (Gorge et al. 2015).

What is relevant to the current discussion is the notion that scarce consumption may arise either nonvoluntarily or voluntarily. Firstly, nonvoluntary simplifiers limit their consumption because they have to do so in order to survive (Gorge et al. 2015; Leipämaa-Leskinen et al. 2016). These individuals are referred to as low-income or poor consumers. Although poor consumers have received much less attention among consumer and marketing scholars than have more fortunate consumers, there is a stream of research that has explored the poor's experiences and survival strategies in welfare societies (for example, Ekström and Hjort 2009; Hamilton and Catterall 2005, 2007; Hill 2002). Naturally, the definition of a poor consumer is connected to material things, that is, goods and services that are needed in daily life. For instance, Darley and Johnson (1985, p.206) define low-income consumers as "individuals whose financial resources or income results in them being unable to obtain the goods and services needed for an 
'adequate' and 'socially acceptable' standard of living." Hence, the challenge of being poor is not only one of material scarcity, but is for the most part linked with stigmatization (Hamilton 2012). Bauman (2005) also addresses social marginalization, stating that the poor have been described as unwanted, abnormal, nonconsumers, and flawed consumers. A number of studies have shown that people who are poor do not simply surrender to the role of vulnerable consumer, but in fact retain agency in their consumption practices (Hamilton 2012; Hamilton and Catterall 2005; Leipämaa-Leskinen et al. 2016); however, pride has rarely emerged as a core finding in prior investigations.

In the case of voluntary scarcity, various definitions have been presented depending on whether the question is about voluntarily simplifying, downshifting, or frugal consumers. In voluntary scarcity, consumers always share the ideology-based drive to consume less (Cherrier and Murray 2002; Shaw and Newholm 2002). Etzioni (1998, p.620), for instance, addresses voluntary simplification as a "choice out of free will," as it aims to "limit expenditures on consumer goods and services, and to cultivate non-materialistic sources of satisfaction and meaning." There has been debate as to whether such people's motives are altruistic or whether it is a proud choice in support of the individual's own wellbeing (Etzioni 1998; Huneke 2005; Shaw and Moraes 2009). Thus, the two conditions of scarcity just set out appear distinctly different in terms of pride.

\section{METHODOLOGY}

The current data consist of real-life narratives that are produced by Finnish consumers living with scarce resources. We analyze narratives within the frames of interpretive approach (Shankar et al. 2001), in which it is considered that through narratives people learn about who they are and their history and culture, and by telling stories people make themselves and their lives understandable to others (Thompson 1997). Thus, narratives are subjectively constructed through language, but shaped and modified by the social and cultural worlds in which they have come into being (Shankar et al. 2001). The narrative material is based on two distinct sources of data. The first set of data is poverty narratives, published in two anthologies called Everyday Experiences of Poverty (Isola et al. 2007; Isola 2012). The narratives were entries in a national writing competition held in 2006 
and its followup writing call in 2012. In total, they include 236 short narratives, varying in length from 1 to 20 pages. The data are available for research purposes in the Finnish social science data archive. They are based on the informants' subjective evaluations of their poverty, and therefore do not represent an objectively representative view of poor people's lives in Finland.

The second group of data was generated in the form of virtual blogs written by individuals who follow the voluntary simplification lifestyle. More precisely, they can be referred to as "ethical simplifiers," because they seek to decrease their consumption primarily for ecological reasons (Shaw and Newholm 2002). In total, six blogs were chosen for the analysis, each of which included entries over the course of several years (from 2009 to 2011). The data accounted for 481 pages of text in total. The blogs were found with the Google search engine using terms such as "simplifying," "downshifting," and "ecological lifestyle." As a result, 14 female bloggers were contacted and asked for permission to use their texts for research purposes, and six blogs were included in the final analysis. We used only writing published before we had contacted the blogger, in order to guarantee the authenticity of the data. The two sets of data differ in terms of the audience they are produced for: Blogs seem more public, being written for other people to read and possibly learn from. Also, the poverty narratives were produced for others to read, and consequently these do not represent completely private writings either. Thus, although constructed through different frames of production, both data sets contain certain ideological aspirations that need to be recognized when interpreting the findings.

The guiding question for the analysis was: How do nonvoluntary and voluntary simplifiers talk about pride in the given sociocultural context? To open up the multifarious facets of pride, we searched for discussions centered on pride and its related manifestations and emotions, such as shame, ego, assertion, elitism, and arrogance. Thus, the analytical process followed Thompson's guidelines for interpreting stories through alternating phases of emic and etic views (Thompson 1997). Our findings highlight two intersecting categories of pride: "forbidden fruit," sourced from the poor consumers' stories, and "hidden heroism," emerging in the voluntary simplifiers' stories. As illustrated in the following sections, together these categories construct the third, "silenced" facet of pride, to stand alongside excessive and authentic pride. 


\section{FINDINGS}

Below we report our findings. We start with descriptions by poor consumers and continue with the viewpoints of voluntary simplifiers. Verbatim quotes from the data are used to support the interpretations.

\section{Forbidden fruit: Pride in nonvoluntary scarcity}

In poor consumers' narratives, pride often appears as something that is inherent in more fortunate people but socially forbidden for the poor. The categorization between people who may experience and express pride and those who are not allowed to signals that pride is very much related to social inclusion and exclusion. In the current data, the social processes of pride were described in connection with gratitude (Soscia 2007). This means that the poor consumers felt they had to be grateful for any help they were given and careful not to express pride in communication with other people, for instance through refusing available material support. This acceptance of what one is given is exemplified in the following narrative:

In the discourse of poverty, the poor is not allowed to have any pride, but she gratefully has to accept all the things that are given to her. The more you live, the more you realize that it is the wealth of a person that determines her dignity. You have to succeed in order to be something. (Female, 27)

This quote also illustrates that pride is seen as a result of an individual's own actions and is attached to her achievements and possessions (Decrop and Derbaix 2010; Zammuner 1996). In this kind of talk, pride was connected with materialistic values and thus seen as out of reach for poor consumers, who feel shame rather than pride. In this sense, the current data supports discussions in which pride and shame are regarded as counterpart emotions (Aaker and Williams 1998; Bagozzi et al. 1999). The disdain shown by other people is well described in the following quote:

Once I heard how a stylish lady disapproved to another lady those shameless people who carry out money from the hatch in the social service office. I have visited on this hatch myself, although there actually isn't any "hatch." There was only a table and a chair behind it. To whom would 
you present your bank account, rent receipts and recipes into? How would you tell to an unknown person that you are not going to make it on your own? (Female, 29)

Sometimes such disdain was even shown by the official authorities, whose task is to evaluate whether or not an individual is allowed financial support on social grounds. Consequently, the data included talk of situations in which the poor people had to swallow their pride. Often these situations were meetings with social security officers or visits to food aid events organized by local charitable organizations. Such a situation is difficult for a poor consumer: On the one hand she is relieved, but on the other, the feelings of shame are tangible. In the following, this controversy is described:

The man encourages me saying: "Take as much you just are able to carry; they will be given to horses otherwise because you are the last client today." Thrilled by this comment, I grasp still a few muesli breads and a pile of rolls. My cheeks start to burn, I feel myself as a greed hoarder. I thank the man and leave. Swallowing my pride I go down the stairs and I do feel strange but at the same time satisfied. (Female, 45)

Social exclusion is illuminated in many of the narratives. This signals the moral aspects of pride (Jasper 2011), because while the poor swallowed their pride, they also felt disapproval aimed at themselves and disconnection from more affluent people. Aligned with prior studies (Ekström and Hjort 2009; Hamilton 2012; Hamilton and Catterall 2007), we found that scarcity, as such, is regarded as a lesser evil than the isolation that eventually follows from being poor. When one is surrounded by people who can afford goods and services that are out of one's reach, one is left aside in many situations, such as party and journey invitations, which are taken for granted by more fortunate people. This marginalization is connected with pride and social exclusion, as described in the following quote:

They say that the bread [queue] is the measure for the poverty. It is not like that. Poverty means loneliness, disappearing friends and no one asking you for a visit or to join a trip, because "he anyway cannot afford to." They are not even asking anymore. And I would not dare to go for a visit with a bag of macaroni. It is not about the pride, but because you find it hard to look at the grill steaks and wine bottles that other people have. The poor person sits on a couch and looks through the window. (Male, 43) 
Despite all the disdain and shame depicted in the data, the poor expressed pride regarding certain issues. Contrary to prior investigations considering more affluent consumers (Huang et al. 2014; McFerran et al. 2011), these were not issues of materialistic goods (for example, luxury products); neither were they based on achievements that are generally regarded as targets of pride, such as career, education, or social status. Instead, the poor were proud of things that money cannot buy, including children, one's own health and that of family members, surviving hard times, and little things such as a beautiful flower bed in the garden. In this regard, the pride experienced resembles authentic pride (Tracy and Robins 2007), as its sources are proper and genuine. The following quote exemplifies how this kind of appreciation of an unmaterialistic way of life is handed down from parents to children:

I am proud of my two children. The other is already grown-up and the other follows after few years. They have grown up as fantastic, mature young ladies who have a good self-esteem and good life values. They are certainly not spoiled with material things. New clothes, makeups or partying are not the most important issues for them. They know how to be satisfied with small things life gives. (Female, 43)

\section{Hidden heroism: Pride in voluntary scarcity}

Although voluntary simplifiers have previously struggled with issues that are out of reach for most of the poor consumers, such as a career-oriented lifestyle, the sources of pride in the stories were similar for both consumer groups. Indeed, voluntary simplifiers describe how their experiences and the causes of their pride have in many ways altered over the course of their lifestyle changes. While they previously felt proud of their shopping-related lifestyles, material goods, and career success, those issues had come to be regarded as blameworthy and even tragic, as illustrated in the following:

Yet in the beginning of this year, I was a female incarnation of materialism who was shopping because of being bored and said sometimes that the quota for daily exercise is completed by shopping for five hours. So, it is clear that I did buy unnecessary things for nothing! Naming me as a shopaholic was actually a source for being proud of, but now I have moved upward from that. Or downward? I guess, that depends who you are asking. (Blog 4) 
Things that had come to generate feelings of pride for the voluntary simplifiers were connected with scarcity, such as declining to buy certain items, reducing consumption in general, and nonmaterialistic issues such as finding more time to be with friends and to improve one's wellbeing. These were strived for and therefore caused positive, authentic experiences of pride. A few prior investigations have presented similar findings showing that consumers make more ethical choices when feelings of pride and guilt are elicited (Antonetti and Maklan 2014). This is because pride appears as a selfconscious and selfregulated emotion, and the causal attribution between pride and one's own actions encourages individuals to behave according to their ideals and values (Baumeister 2002). The following quote illustrates how one informant was secretly proud of her good actions:

I live in a house with seven floors. The lights are "switched off automatically" ... in each floor, except the basement. When I was carrying my laundry to the laundry room, I noticed the light was on totally unnecessarily. I played an eco-angel and switched it off, because I could see well in natural light. And once again I secretly was proud of myself, because previously I probably would have kept the light on. (Blog 4)

The quote exhibits one example of "hidden heroism" found in the data. In this regard, both nonvoluntary and voluntary simplifiers seem to manifest pride in a silent manner, keeping it secret from others. One explanation for this may be the deeply rooted Protestant ethic in the Finnish culture (Heinonen and Autio 2013). Although the Protestant ethic is typically connected with appreciating hard work and disapproving of unnecessary consumption, it may generate a spirit of "hiding one's light under a bushel" in all kinds of situations where one's superiority over others is to be shown. Dandyism is indeed something that is deeply disapproved of in the Finnish sociocultural milieu (ibid.). Consequently, the social marginalization of pride is also demonstrated in the case of voluntary simplicity, as the data included many examples of the simplifiers experiencing social isolation (Cherrier et al. 2012; Gorge et al. 2015). The culturally constructed moral and social aspects of pride thus emerge in both nonvoluntary and voluntary scarcity. The quote below exemplifies one blogger's experience of other people often questioning her ecological choices and even silencing her in social situations: 
How people who are interested in ecological issues and wellbeing handle the "ordinary" people's laughing and diminishments? I have constantly during these years prompted with them, and this is why I have sometimes hided this side of me even so much that I lost the ecological and wellbeing related thinking even from myself . . . I'm used to keeping these issues in silence, although I'd like to talk about them, tell about my nice findings, and good experiences, share my thoughts with curious people. However, I cannot do it, because then immediately people start to pressure myself for becoming normal, that is, they will show me my stupidity in spite of how much I tell about my good experiences. This is where the discussion often ends up. (Blog 2)

The data further illuminated how other people sometimes labeled the voluntary simplifiers as living in a selfish and elitist way. In this regard, the simplifiers are accused of hubristic pride (Verbeke et al. 2004), as they are seen to consider themselves as superior people with the privilege to address issues that other people may not be able to. Often these accusations were intertwined with discussion of labor, and because some of the voluntary simplifiers had decreased their working hours or left work, they were faced with assumptions that they were not doing their share to keep society competitive. The simplifiers defended themselves by highlighting improvements to their mental and physical welfare that may actually make them more productive than was previously the case, and from their own viewpoint, their lifestyle did not lead to excessive pride. Reflecting this heated debate in a blog post, one informant presents multifarious responses to the arguments of elitism, taking a stand on the situation of the poor too:

\begin{abstract}
And yet, we do have our own poor people too, and in front of their problems this kind of downshifters' giving up is really light stuff and feels like corny, of course . . . At least for me, the loose time use, which has been possible after downshifting, has enabled me to analyze these issues overall, and following from that, to perform [a] much more ecological, ethically sustainable, and creative lifestyle which I find difficult to define as an elitist action at all, at the level of everyday solutions. (Blog 6)
\end{abstract}

As our informants represented the so-called ethical simplifiers (Shaw and Newholm 2002), the data included various writings in which the ultimate reasons for the present unsustainable levels of consumption in Western society were pondered. The bloggers often depicted materialism and the continual desire for novel objects of consumption as drivers for people's repeated desire to carry out practices (for example 
overwork) which are eventually harmful for everyone (Belk 1983). As one informant put it: "Anyhow, I suppose that a big mass of these middle class, Western people is suffering from their ego's compelling wanting, which always drives us somehow to the accident" (Blog 1).

\section{DISCUSSION AND CONCLUSIONS}

In this chapter, we have revisited the sin of pride in consumer research. The current findings highlight that pride does not only consist of two facets - excessive and authentic - but, when explored in conditions of scarce consumption, appears silenced by the surrounding consumer society. Table 1.1 summarizes these three facets of pride to highlight the conceptual distinctions between them.

Below, we open up the conceptual elements of silenced pride more specifically. While consumers living in abundance may express pride either as unwarranted self-sufficiency or as genuine satisfaction, for the (non)voluntary simplifiers, pride appears as either forbidden or hidden emotion. This resembles the findings of Decrop and Derbaix (2010) about sports fans' hidden pride over private soccer-related objects that were not shared publicly. However, while the sports fans could choose to either hide or express their pride (ibid., p.594), our data revealed that the simplifiers had to hide or swallow their pride due to social pressures. For instance, the poor described how they had to be content with any help given to them. Thus, although charity work and social benefits are necessary for the poor, and sometimes their last chance of survival, from the viewpoint of pride it is problematic if people who offer charity are regarded as superior to the poor. Then the same situation may cause feelings of pride for the helper, but at the same time feelings of shame for the person receiving the material support. Similarly, in the case of voluntary simplifiers, pressures from the surrounding consumption-oriented society drove them to express their feelings of pride stemming from their ability to consume less only in secret. Whereas in matters of excessive and authentic pride, social surroundings act as stepping stones for these feelings, in this situation social surroundings silence those experiences for the (non)voluntary simplifiers.

When it comes to manifestations of pride in consumption, our data show that both nonvoluntary and voluntary simplifiers talked about the matter in connection with immaterial things or performance, and 
Table 1.1 Three facets of pride

\begin{tabular}{|c|c|c|c|}
\hline & Excessive pride & Authentic pride & Silenced pride \\
\hline As emotions & $\begin{array}{l}\text { Unwarranted } \\
\text { self-sufficiency }\end{array}$ & $\begin{array}{l}\text { Satisfaction, delight, } \\
\text { or pleasure }\end{array}$ & $\begin{array}{l}\text { Forbidden/ } \\
\text { hidden } \\
\text { pleasure }\end{array}$ \\
\hline Relation to self & $\begin{array}{l}\text { Self- } \\
\text { consciousness, } \\
\text { egoism, } \\
\text { self-importance, } \\
\text { vanity }\end{array}$ & $\begin{array}{l}\text { Helps to act } \\
\text { according to one's } \\
\text { values, self-appraisal }\end{array}$ & $\begin{array}{l}\text { Inferiority, but } \\
\text { also a secret } \\
\text { pleasure }\end{array}$ \\
\hline $\begin{array}{l}\text { Relation to } \\
\text { social processes }\end{array}$ & $\begin{array}{l}\text { Arrogance, } \\
\text { disregard of the } \\
\text { worth of others }\end{array}$ & $\begin{array}{l}\text { Supports social } \\
\text { identity processes, } \\
\text { other people's } \\
\text { opinions influence } \\
\text { identity }\end{array}$ & $\begin{array}{l}\text { Social } \\
\text { exclusion } \\
\text { dictates the } \\
\text { rules: pride is } \\
\text { not allowed }\end{array}$ \\
\hline $\begin{array}{l}\text { Manifestations } \\
\text { in consumption }\end{array}$ & $\begin{array}{l}\text { Conspicuous } \\
\text { status and } \\
\text { prestige-seeking } \\
\text { consumption; } \\
\text { materialism }\end{array}$ & $\begin{array}{l}\text { Emotional, positive } \\
\text { mediator in } \\
\text { consumption and } \\
\text { marketing behavior }\end{array}$ & $\begin{array}{l}\text { Immaterial } \\
\text { things in life, } \\
\text { surviving with } \\
\text { less }\end{array}$ \\
\hline Opposites & $\begin{array}{l}\text { Courage, } \\
\text { modesty, or } \\
\text { humility }\end{array}$ & Shame, guilt & $\begin{array}{l}\text { Gratitude, } \\
\text { shame }\end{array}$ \\
\hline Sources & $\begin{array}{l}\text { Relates to one's } \\
\text { qualities }\end{array}$ & $\begin{array}{l}\text { Relates especially to } \\
\text { one's achievements } \\
\text { and their outcomes, } \\
\text { but also to } \\
\text { possessions }\end{array}$ & $\begin{array}{l}\text { Relates } \\
\text { to one's } \\
\text { achievements } \\
\text { and } \\
\text { immaterial } \\
\text { possessions }\end{array}$ \\
\hline
\end{tabular}

not in relation to achieving status or gaining prestigious possessions. Hence, while pride has previously been connected with objects that help someone win social admiration (Zammuner 1996), such as luxury products and brands (Huang et al. 2014; McFerran et al. 2011), our informants were proud of their social relationships and mental wellbeing. Moreover, the poor respondents were proud of their survival ability (Gorge et al. 2015; Hamilton 2012), and the voluntary simplifiers of their daily green behaviors. These performances showed that an individual was behaving according to her ideals, and seemed to trigger feelings of positive pride (Antonetti and 
Maklan 2014; Onwezen et al. 2014). In this respect, pride in scarcity resembles experiences of authentic pride.

What about the sinful facets of pride, then? Our findings show evidence of excessive pride emerging in descriptions of how other people were blaming the voluntary simplifiers for their "lazy and convenience seeking" lifestyles, and especially for their decisions to resign from their jobs and aim to reduce their consumption. This kind of talk exemplifies the negative facets of pride, as the voluntary simplifiers were accused of being elitists and arrogant individuals who saw themselves as superior to others (Tracy and Robins 2007). The poor respondents, on the other hand, were victims of excessive pride: Affluent people showed arrogance toward them and sometimes acted as if the former were themselves guilty for their distress. They were treated as inferior people who should be grateful for any support they were offered. Our findings in this regard differ sharply from prior discussions, which have connected "pride as a sin" with materialism and prestige consumption (Belk 1983), and certainly not with consumers who are voluntarily or involuntarily limiting their consumption.

To conclude, both sets of data indicate that pride as a sin takes place in social processes when someone acts arrogantly and disregards the worth of others. Since most of the prevailing consumer studies have conceptualized pride as an individual-level phenomenon, the social and cultural dynamics of pride deserve more attention in future studies. At present we can speculate that the sinful facets of pride may originate in situations where individuals differ in their values, norms, and lifestyles, such as voluntary simplifiers and people who appreciate the traditional "work hard and do your bit" way of living, as well as poor and more affluent people. It seems that pride as a moral emotion may serve as a useful theoretical construct to explore social connections and disconnections between people.

\section{REFERENCES}

Aaker, J \& Williams, P 1998, "Empathy versus pride: The influence of emotional appeals across cultures," Journal of Consumer Research, vol. 25, December, pp.241-61.

Antonetti, P \& Maklan, S 2014, "Feelings that make a difference: How guilt and pride convince consumers of the effectiveness of sustainable consumption choices," Journal of Business Ethics, vol. 124, no. 1, pp.117-34. 
Bagozzi, RP, Baumgartner, H \& Pieters, R 1998, "Goal-directed emotions," Cognition and Emotion, vol. 12, no. 1, pp.1-26.

Bagozzi, RP, Gopinath, M \& Nyer, PU 1999, "The role of emotions in marketing," Journal of the Academy of Marketing Science, vol. 27, no. 2, pp.184-206.

Bauman, Z 2005, Work, Consumerism and the New Poor, Buckingham: Open University Press.

Baumeister, RF 2002, "Reflections and reviews impulsive purchasing, and consumer behavior," Journal of Consumer Research, vol. 28, no. 3, pp.670-77.

Belk, RW 1983, "Worldly possessions: Issues and criticisms" in RP Bagozzi \& AM Tybout (eds), Advances in Consumer Research, vol. 10, pp.514-19. Ann Arbor: Association for Consumer Research.

Bellezza, S \& Keinan, A 2014, "Brand tourists: How non-core users enhance the brand image by eliciting pride," Journal of Consumer Research, vol. 41, August, pp.397-417.

Boezeman, EJ \& Ellemers, N 2007, "Volunteering for charity: Pride, respect, and the commitment of volunteers," Journal of Applied Psychology, vol. 92, no. 3, pp.771-85.

Burroughs, JE \& Rindfleisch, A 2012, "What welfare? On the definition and domain of transformative consumer research and the foundational role of materialism" in DE Mick, S Pettigrew, C Pechmann, \& JL Ozanne (eds), Transformative Consumer Research-For Personal and Collective Well-Being, pp.249-66. London: Routledge.

Caywood, CL \& Langrehr, FW 1990, "Definitional issues related to using the seven sins and seven virtues as a model for advertising analysis," Current Issues and Research in Advertising, vol. 12, no. 1-2, pp.43-62.

Cherrier, H \& Murray, J 2002, "Drifting away from excessive consumption: A new social movement based on identity construction" in SM Broniarczyk \& K Nakamoto (eds), Advances in Consumer Research, vol. 29, pp.245-7. Valdosta, GA: Association for Consumer Research.

Cherrier, H, Szuba, M, \& Özçağlar-Toulouse, N 2012, "Barriers to downward carbon emission: Exploring sustainable consumption in the face of the glass floor," Journal of Marketing Management, vol. 28, no. 3-4, pp.397-419.

Darley, WK \& Johnson, DM 1985, "A contemporary analysis of the low income consumer: An international perspective" in C Tan \& JN Sheth (eds), Historical Perspectives in Consumer Research: National and International Perspectives, pp.206-10. Provo, UT: Association for Consumer Research.

Decrop, A \& Derbaix, C 2010, "Pride in contemporary sport consumption: A marketing perspective," Journal of the Academy of Marketing Science, vol. 38, no. 5, pp.586-603.

Ekström, KM \& Hjort, T 2009, "Hidden consumers in marketing: The neglect of consumers with scarce resources in affluent societies," Journal of Marketing Management, vol. 25, September, pp.697-712.

Etzioni, A 1998, "Voluntary simplicity: Characterization, select psychological implications, and societal consequences," Journal of Economic Psychology, vol. 19, no. 5, pp.619-43. 
Fullerton, RA \& Punj, G 1998, "The unintended consequences of the culture of consumption: An historical-theoretical analysis of consumer misbehavior," Consumption, Markets \& Culture, vol. 1, no. 4, pp.393-423.

Gorge, H, Herbert, M, Özçağlar-Toulouse, N, \& Robert, I 2015, "What do we really need? Questioning consumption through sufficiency," Journal of Macromarketing, vol. 35, no. 11, pp.11-22.

Hamilton, K 2012, "Low-income families and coping through brands: Inclusion or stigma?" Sociology, vol. 46, no. 1, pp.74-90.

Hamilton, K \& Catterall, M 2005, "Towards a better understanding of the low-income consumer" in G Menon \& AR Rao (eds), Advances in Consumer Research, vol. 32, pp.627-32. Provo, UT: Association for Consumer Research.

Hamilton, K \& Catterall, M 2007, "Keeping up appearances: Low-income consumers' strategies aimed at disguising poverty" in M Lees, M Davis, \& G Gregory (eds), Asia-Pacific Advances in Consumer Research, vol. 7, pp.184-9. Provo, UT: Association for Consumer Research.

Heinonen, V \& Autio, M 2013, "The Finnish consumer mentality and ethos: In the intersection between east and west" in V Heinonen \& M Peltonen (eds), Finnish Consumption! An Emerging Consumer Society between East and West (Studia Historica 83), pp.42-85. Helsinki: Finnish Literature Society.

Hill, RP 2002, "Consumer culture and the culture of poverty: Implications for marketing theory and practice," Marketing Theory, vol. 2, September, pp.273-93.

Holbrook, M \& Hirschman, E 1982, "The experiential aspects of consumption: Consumer fantasies, feelings, and fun," Journal of Consumer Research, vol. 9, no. 2, pp.132-40.

Huang XI, Dong P, \& Mukhodaphyay, A 2014, "Proud to belong or proudly different? Lay theories determine contrasting effects of incidental pride on uniqueness seeking," Journal of Consumer Research, vol. 41, October, pp.697-712.

Huneke, ME 2005, "The face of the un-consumer: An experimental examination of the practice of voluntary simplicity in the United States," Psychology \& Marketing, vol. 22, no. 7, pp.527-50.

Isola, AM 2012, Everyday Experiences on Poverty: Follow-Up Data 2012 [electronic data, translated from Finnish], version 1.0 (2012-12-04), University of Helsinki, available from: http://urn.fi/urn:nbn:fi:fsd:T-FSD2795. Finnish Social Science Data Archive.

Isola, AM, Larivaara, M, \& Mikkonen, J 2007, Everyday Experiences on Poverty [translated from Finnish], Keuruu: Otavan kirjapaino Oy.

Jasper, JM 2011, "Emotions and social movements: Twenty years of theory and research," Annual Review of Sociology, vol. 37, pp.285-303.

Kim, J \& Johnson, K 2013, "The impact of moral emotions on cause-related marketing campaigns: A cross-cultural examination," Journal of Business Ethics, vol. 112, no. 1, pp.79-90.

Lee, MSW, Fernandez, KM, \& Hyman, MR 2009, “Anti-consumption: An 
overview and research agenda," Journal of Business Research, vol. 62, no. 2, pp.145-7.

Leipämaa-Leskinen, H, Syrjälä, H, \& Laaksonen, P 2016, "Conceptualizing non-voluntary anti-consumption: A practice-based study on market resistance in poor circumstances," Journal of Consumer Culture, vol. 16, no. 1, pp. 255-78.

Louro, MJ, Pieters, R, \& Zeelenberg, M 2005, "Negative returns on positive emotions: The influence of pride and self-regulatory goals on repurchase decisions," Journal of Consumer Research, vol. 31, March, pp.833-40.

McFerran, B, Aquino, K, \& Tracy, J 2011, "Evidence for two faces of pride in consumption: Findings from luxury brands," in DW Dahl, GV Johar, \& SMJ van Osselaer (eds), Advances in Consumer Research, vol. 38, pp.479-80. Duluth, MN: Association for Consumer Research.

Onwezen, MC, Bartels, J, \& Antonides, G 2014, "The self-regulatory function of anticipated pride and guilt in a sustainable and healthy consumption context," European Journal of Social Psychology, vol. 44, pp.53-68.

Pepper, M, Jackson, T, \& Uzzell, D 2009, "An examination of the values that motivate socially conscious and frugal consumer behaviours," International Journal of Consumer Studies, vol. 33, no. 2, pp.126-36.

Richins, ML 1997, "Measuring emotions in the consumption experience," Journal of Consumer Research, vol. 24, September, pp.127-46.

Roseman, IJ 1991, "Appraisal determinants of discrete emotions," Cognition and Emotion, vol. 5, no. 3, pp.161-200.

Shankar, A, Elliot, R, \& Goulding, C 2001, "Understanding consumption: Contributions from a narrative perspective," Journal of Marketing Management, vol. 17, no. 3-4, pp.429-53.

Soscia, I 2007, "Gratitude, delight or guilt: The role of consumers' emotions in predicting post-consumption behaviors," Psychology and Marketing, vol. 24, no. 10, pp.871-94.

Timpe, K \& Boyd, GA 2014, "Introduction," in K Timpe \& GA Boyd (eds), Virtues and Their Vices, pp.1-36, Oxford: Oxford University Press.

Thompson, CJ 1997, "Interpreting consumers: A hermeneutical framework for deriving marketing insights from the texts of consumers' consumption stories," Journal of Marketing Research, vol. 34, no. 4, pp.438-55.

Shaw, D \& Moraes, C 2009, "Voluntary simplicity: An exploration of market interactions," International Journal of Consumer Studies, vol. 33, no. 2, pp. 215-23.

Shaw, D \& Newholm, T 2002, "Voluntary simplicity and the ethics of consumption," Psychology \& Marketing, vol. 19, no. 2, pp.167-85.

Tracy, JL \& Robins, RW 2004, "Show your pride: Evidence for a discrete emotion expression," Psychological Science, vol. 15, no. 3, pp.194-7.

Tracy, JL \& Robins, RW 2007, "The psychological structure of pride: A tale of two facets," Journal of Personality and Social Psychology, vol. 92, no. 3 , pp.506-25.

Verbeke, W, Belschak, F, \& Bagozzi, RP 2004, "The adaptive consequences of pride in personal selling," Journal of the Academy of Marketing Science, vol. 32 , no. 4 , pp.386-402. 
Wilcox, K, Kramer, T, \& Sankar, S 2011, "Indulgence or self-control: A dual process model of the effect of incidental pride on indulgent choice," Journal of Consumer Research, vol. 38, June, pp.151-63.

Zammuner, VL 1996, "Felt emotions, and verbally communicated emotions: The case of pride," European Journal of Social Psychology, vol. 26, no. 2, pp.233-45. 